\title{
Effectiveness of Using an Instructional Video in Teaching Light-Curing Technique
}

This article was published in the following Dove Press journal:

Advances in Medical Education and Practice

\author{
Afnan O Al-Zain (iD \\ Tasneem M Al-Osaimi \\ Restorative Dentistry Department, \\ Faculty of Dentistry, King Abdulaziz \\ University, Jeddah, Saudi Arabia
}

Correspondence: Afnan O Al-Zain Restorative Dentistry Department, King Abdulaziz University Faculty of Dentistry, P.O. Box 80209, Jeddah, 21589, Saudi Arabia

Tel +966539116467

Fax +9666403316

Email alzain@kau.edu.sa
Purpose: To investigate dental students' ability to deliver satisfactory amounts of irradiance and radiant exposure to simulated cavities by teaching the light-curing technique using instructional video compared to verbal instructions.

Methods: Students attended the didactic light-curing lecture explaining the light-curing technique. Participants were divided into two groups $(n=60)$. Each participant light-cured a class III and a class I simulated cavities with sensors built-in a Managing Accurate Resin Curing-Patient Simulator (MARC-PS) system, using a multiple-emission-peak light-emitting-diode unit. Each student either 1) watched an instructional video (V) showing the light-curing technique, or 2) received individual verbal instruction (I). The light-curing performance, in terms of the mean irradiance and radiant exposure, was recorded. Each student performed light-curing again on the simulated cavities. Students' feedback for the corresponding teaching method was collected. Comparisons between before and after each instructional method were analyzed using the Wilcoxon signed-rank test. Comparisons between both instructional methods were analyzed using a MannWhitney $U$-test $(\alpha=0.05)$.

Results: The students' light-curing performance improved after both methods, as observed on the MARC-PS laptop monitor. The mean irradiance values were anterior-V $=1280.6$ (183.2), anterior-I=1318.0 (143.5), posterior- $\mathrm{V}=1337.5$ (181.1), posterior- $\mathrm{I}=1317.6$ (248.2) $\mathrm{mW} / \mathrm{cm}^{2}$. The mean radiant exposure values were for anterior- $\mathrm{V}=13.5(2.7)$, anterior- $\mathrm{I}=13.3$ (1.6), posterior- $\mathrm{V}=13.7$ (1.9), posterior-I=13.7 (2.5) $\mathrm{J} / \mathrm{cm}^{2}$. No significant difference was found between both instruction methods. Students reported that each method was effective. Conclusion: Using V was comparable to I and an effective tool for teaching the light-curing technique per the students' ability to deliver sufficient amounts of irradiance and radiant exposure to simulated cavities.

Keywords: education, light-curing unit, patient simulator, psychomotor performance, irradiance, radiant exposure

\section{Introduction}

In most dental schools, less emphasis and time are spent by the Operative Dentistry courses to teach and develop accurate light-curing technique skills, which might affect the quality of light-activated restorations performed by dental students. ${ }^{1}$ Therefore, students need to acquire the correct light-curing technique skills in the preclinical laboratory to activate polymerization reaction effectively. ${ }^{2,3}$ Ineffective light-curing technique can negatively impact some material properties, including; color stability, bond strength, and marginal integrity, ultimately affecting the restorations' longevity. ${ }^{2-7}$ Hardening of the restoration top does not indicate that 
it is effectively cured. Also, it does not indicate that sufficient radiant exposure was delivered to the restoration's bottom. ${ }^{2}$

Live demonstration in teaching laboratory techniques is the traditional and the most common method for educating dental students. ${ }^{8}$ It enhances the students' confidence and communication skills and their understanding better than learning those skills in lectures. ${ }^{9}$ However, other factors should be controlled to ensure its effectiveness; as the number of faculty members, faculty to students' ratio, visualization difficulty, and the time it consumes. ${ }^{10}$ Several studies investigated various strategies to teach and develop students' psychomotor skills, including instructional videos. ${ }^{8,10-12}$ Students have different learning preferences and perceive information in different ways. ${ }^{13,14}$ When instructional videos were used in addition to traditional classroom teaching, students' cognitive and psychomotor skills were enhanced with an improvement in their knowledge retention. ${ }^{15,16}$ Also, the confidence increased when performing specific procedures such as teaching local anesthesia administration. ${ }^{16,17}$ It was shown that using video was valuable in didactic means and should be considered for teaching dental students. ${ }^{18,19}$ Interestingly, using an instructional video to evaluate the effectiveness of teaching the light-curing technique had not yet been investigated. In our institute, using instructional videos to teach the different procedures in the Preclinical Operative and Esthetic Dentistry course was introduced in the 2017-18 academic year. Thus, exploring different teaching methods in the preclinical laboratory was worth investigating.

Incorporating simulation technology in education is beneficial to support the obtainment of psychomotor skills prior to clinical application. ${ }^{20-22}$ A Managing Accurate Resin Curing-Patient Simulator (MARC-PS) was developed as an educational tool to teach students the light-curing technique while providing immediate visual feedback on a laptop monitor. ${ }^{1,23-25}$ Training of light-curing skill on the MARCPS improved the students' performance. ${ }^{1,26-28}$ Training tools with digital visual feedback can help teach students complex practical procedures. ${ }^{1,26-28}$ Literature showed that using MARC-PS when providing individualized verbal coaching instructions helped teach light-curing technique and deliver sufficient amounts of radiant exposure to the simulated cavity. ${ }^{1,27,28}$ Furthermore, MARC-PS provides objective measurements in terms of providing calculated irradiance and radiant exposure values delivered to the simulated cavities in addition to the graphs that provide immediate visual feedback to students. ${ }^{1,27,28}$ Therefore, exploring the effectiveness of using an instructional video $(\mathrm{V})$ to demonstrate the light-curing technique to dental students compared to individualized verbal instructions (I) using a patient simulator was worth exploring.

Students' didactic and preclinical performance is evaluated through a series of formative and summative assessments. $^{29}$ The didactic component includes several components such as examinations, assignments, and group work. ${ }^{29}$ The practical components include different cavity classes and designs, restorations, adjunctive procedures, and competencies. ${ }^{29}$ Therefore, it was interesting to explore the association between students' light-curing performance and course grade.

The study aimed to investigate: (1) the students' ability to deliver sufficient amounts of irradiance and radiant exposure to simulated cavities by teaching students the light-curing technique using instructional video compared to verbal instructions. (2) the effectiveness of an instructional video compared to verbal instructions for teaching light-curing. (3) the correlation between the instructional method and the student's score in the Preclinical Operative and Esthetic Dentistry course. The working hypotheses were: (1) students' ability to deliver sufficient amounts of irradiance and radiant exposure to simulated cavities is significantly higher when using instructional video compared to verbal instructions. (2) an instructional video is significantly more effective than verbal instructions when teaching light-curing. (3) there is a significant correlation between the instructional method and the student's score in the Preclinical Operative and Esthetic Dentistry course.

\section{Materials and Methods Study Design Experiment Preparation}

The IRB approval was obtained from the Research Ethics Committee at King Abdulaziz University Faculty of Dentistry (IRB approval no.:105-10-18). The undergraduate dental studies at King Abdulaziz University is a sixyear program. The study was conducted in February 2019, and the target dental students were third-year students, where it was their first exposure to the Preclinical Operative and Esthetic Dentistry course. Students were of similar age (21- to 24-year-old), and exposed to the same lectures and had a similar knowledge level.

A MARC-PS spectrometer (BlueLight Analytics Inc., Halifax, Canada) was used to collect irradiance and radiant 
exposure measurements. This device uses a spectrometer that accurately measures the irradiance and radiant exposure received by an anterior and posterior simulated cavity in a mannikin head. The anterior sensor is placed between teeth number 11 and 21 according to the FDI teeth numbering system and is $1-\mathrm{mm}$ recessed from the surface, simulating a class III cavity. The posterior sensor is placed on tooth number 27 and is $4-\mathrm{mm}$ recessed from the surface, simulating a class I cavity. The irradiance, radiant exposure, and spectral distribution received by the simulated cavities are displayed on a laptop monitor. The accuracy of the performance is presented in graphs, and results are viewed in real-time to provide immediate visual feedback about the student's light-curing technique. This information is valuable because the results can be translated into irradiance and radiant exposure amounts received by the restorations in a clinical setting. $1,23,24$ None of the students had used the MARC-PS spectrometer before the experiment but were using a similar manikin phantom head in their Preclinical Operative and Esthetic Dentistry course.

One of the authors and an expert in the field tested the multiple-emission peak light-emitting-diode lightcuring unit (LCU) (Bluephase N, Ivoclar Vivadent, Schaan, Liechtenstein). The expert measured the irradiance and radiant exposure as detected by the anterior and posterior teeth over 10 seconds to record the maximum measurements obtained $(n=3)$. The faculty expert recorded a video of the light-curing technique to demonstrate the technique to cure the designated MARC-PS teeth. The video was three minutes long and included narration and subtitles, which described the light-curing steps and demonstrating how to perform the curing technique on the MARC-PS on the anterior and posterior teeth (Supplementary Material 1). Two examiners that conducted the experiment were calibrated using the MARC-PS and were informed what the students were taught during the lecture. The examiners' verbal instructions were standardized with a script of the light-curing steps similar to the video and also approximately three minutes long with the demonstration. The examiners described the light-curing steps and demonstrated inperson the curing technique on the MARC-PS on the anterior and posterior simulated cavities.

The total number of students in the class was 202; 114 females and 88 males. All students performed the experiment to allow a similar learning experience. Participation in the study was vulnerary. A total of 120 students participated in this study, with an equal number of male and female students were in each group. Authors were limited to the maximum number of volunteering male students and refrained from accepting female participants when the maximum number was reached. The experiment took place in the laboratory sessions and was performed for each student individually. Informed consent was obtained from all students prior to study commencement. A serial number and gender identified each student to record measurements before and after the assigned instructional method.

\section{Experiment Laboratory Setup}

The MARC-PS laptop was placed on the benchtop, and the manikin head was mounted on a benchtop in the preclinical phantom laboratory where students' sessions are conducted. A different laptop was placed on the benchtop near the MARC-PS and was used to play the instructional video. A pair of sound cancelation headphones were provided for students to use while watching the video. Two pairs of orange goggles were available on the laboratory bench to see if the student would wear one pair and place the other pair of goggles on the MARC-PS manikin head before conducting the light-curing procedure.

An in-house rubric was created that included the lightcuring steps taught in the lecture for the examiners to evaluate the student's performance (Supplementary Material 2). The LCU was fully charged before use and placed on the charging dock after recording each student's measurements.

\section{Experiment}

Students attended the same "Light-Curing in Dentistry" didactic lecture in a classroom given by the first author. The lecture focused on the science behind light-curing, the factors that affect polymerization effectiveness, and the light-curing technique steps presented in PowerPoint slides. No video and no demonstration were presented in the lecture. Therefore, students received the same level of knowledge in the lecture.

The light-curing technique was taught in the lecture in the following sequence: (1) ensure that the light guide tip is clean from any material remnants and not broken; (2) wear the protective orange blue light blocking goggles; (3) place the protective orange blue light blocking goggles on the patient; (4) place the light-guide tip perpendicular to the surface being cured; (5) place the light-guide tip as close as possible to the surface being cured without touching the surface; (6) use 
A

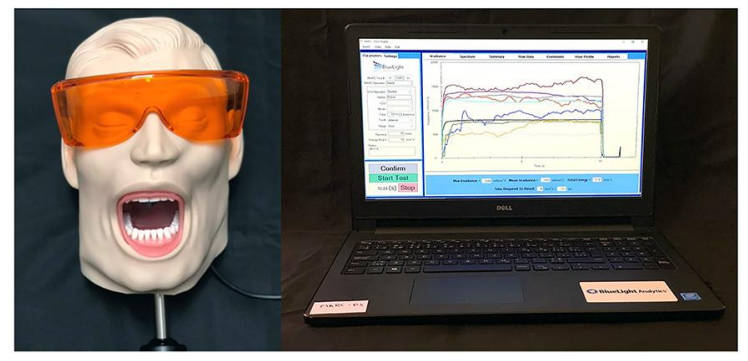

B

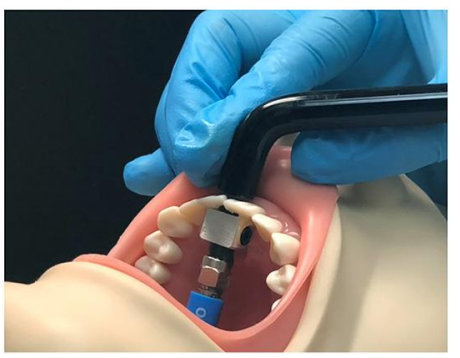

C

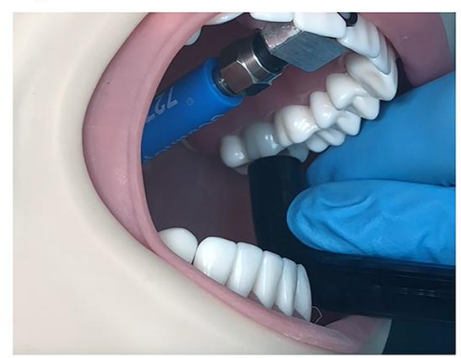

Figure I The Managing Accurate Resin Curing-Patient Simulator (MARC-PS) system. (A) The MARC-PS manikin head is connected to a laptop. (B) Light-curing unit placement on the anterior tooth. (C) Light-curing unit placement on the posterior tooth.

finger support to stabilize the light-guide tip; (7) keep eyes on the filling (pay attention); (8) activate the curing unit for the appropriate curing time according to the manufacturer's recommendation; (9) apply additional curing on the buccal and lingual surfaces for proximal restorations.

Students were randomly assigned into two groups $(\mathrm{n}=60)$; a group watched the instructional video $(\mathrm{V})$, and the other received individualized verbal instructions (I), and the latter was used as the control group. An equal number of males and females were included in each group $(n=30$ males and 30 females/teaching method). Each student performed the experiment by either watching the video individually or received individual verbal instructions. Each student performed the light-curing technique using the MARC-PS by light-curing the built-in anterior and posterior simulated cavities twice each based on the lecture's information and before receiving any instructions (Figure 1). Each student viewed their light-curing performance in real-time in terms of the irradiance graphs, irradiance, and radiant exposure values on the laptop monitor connected to the MARC-PS. The student could not ask the examiner questions to ensure that information was obtained from one source. Moreover, students were not allowed to receive feedback from each other. This was controlled by allowing students to execute the experiment individually, where students did not observe each other performing. After that, students were instructed not to share information regarding the experiment until the experiment was completed. The examiner used the rubric to record whether the students wore the orange goggles and performed each step correctly.

Each student watched the instructional video or was provided with verbal instructions. After the designated instructional method, the student performed light-curing again on both simulated cavities and viewed their performance again in real-time on the laptop monitor. The student was then allowed to ask questions and was provided feedback immediately after the experiment was completed. The study design is presented in Figure 2.

The feedback survey was collected from the students using a google form. It included closed-ended and openended questions. They were asked to (1) rate their perception of the respective teaching method from 1-5 and to provide written comments, (2) select their learning preference (not specific to this experiment), whether V or I or both methods complemented each other, and provide written comments

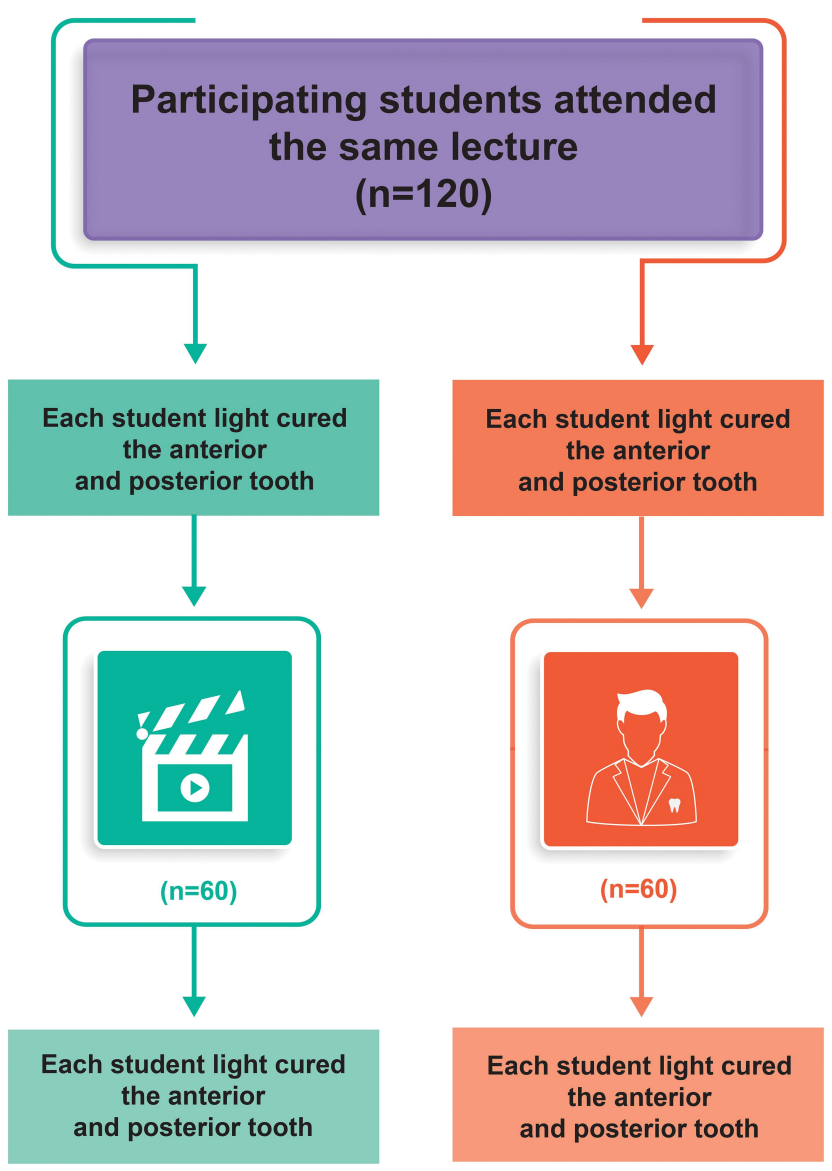

Figure 2 Study design. 
(Supplementary Material 3). A feedback survey was collected from the examiners using a google form with a closed-ended and open-ended questions to record their observations on the students' performance and their comments and observations on both methods (Supplementary Material 4). The Preclinical Operative and Esthetic Dentistry course scores were obtained for each student.

\section{Statistical Analysis}

Evaluation of the effectiveness of the instructional methods was provided through several comparisons. Visual comparisons using the graphs generated from the MARCPS system were performed before and after each instructional method to observe the student's performance. In addition, visual comparisons were performed between the instructional methods to observe the student's performance. Normality was tested using the KolmogorovSmirnov test. For each instructional method, statistical comparisons of the mean irradiance and radiant exposure for each tooth before and after using each method were performed using Wilcoxon signed-rank test.

To account for performance differences that may exist at the baseline for each method (before- $\mathrm{V}$ and before-I), a comparison between both methods was performed by calculating each method's difference (after minus before). Comparing the mean irradiance and radiant exposure values between instructional methods before and then after using each tooth and the percent increase in irradiance and radiant exposure values for each method using each tooth was analyzed using the Mann-Whitney $U$-test.

The correlation between the difference (after minus before) for each instructional method and the student's respective score in the Preclinical Operative and Esthetic Dentistry course was analyzed using Spearman correlation. Comparisons between instructional methods based on the students' feedback scoring were analyzed using the Mann-Whitney $U$-test. Comparisons between the instructional methods and the students' learning preferences based on their feedback scoring were analyzed using the Chi-square test. All tests were performed at a $5 \%$ level of significance. The SPSS software version 25 (IBM Corp., Armonk, NY, USA) was used to perform all statistical calculations and analysis.

\section{Results}

The mean irradiance measured by the expert for the LCU used was 1559.04 (74.77) and $1536.50(46.16) \mathrm{mW} / \mathrm{cm}^{2}$ as detected by the anterior and posterior teeth, respectively.
The expert's radiant exposure measurements were 15.96 (0.79) and $15.73(0.50) \mathrm{J} / \mathrm{cm}^{2}$ as detected by the anterior and posterior teeth, respectively. The percent difference between the expert and students' irradiance and radiant exposure measurements was similar between instructional methods, ranged between 22 to $35 \%$ before receiving instructions, and between 14 to $21 \%$ after both instructional methods, regardless of the tooth position.

Upon experimenting, 68\% did not check if the lightguide tip is clean and not broken, 3\% of students did not wear the blue-light blocker goggles and looked away from the tooth being cured. Moreover, $52 \%$ of the students did not place a pair of blue-light blocker goggles on the patient simulator. Approximately $15 \%$ of the students did not place the LCU guide tip perpendicular to the tooth surface, $20 \%$ did not place the light-guide tip as close as possible to the tooth, $35 \%$ did not place finger support, and $11 \%$ did not keep their eyes on the filling while light-curing.

Concerning $\mathrm{V}$ and I methods, the irradiance graph for both simulated cavities (Figures 3 and 4) showed that the students' light-curing performance before any instructions were similar and inconsistent, which improved after both instructional methods. This was expected and evident in the relatively straighter curves on the graphs representing better hand stability and control during the light-curing procedure. It is also evident in the graphs that students in both groups delivered relatively consistent irradiance values with both instructional methods. It was interesting to see that the students' performance when light-curing the posterior tooth was better than the anterior tooth before receiving any instructions.

For each instructional method, statistical analysis of the mean irradiance and radiant exposure values the students delivered to the simulated cavities showed similar findings. The mean irradiance and radiant exposure values after- $\mathrm{V}$ were significantly higher than before- $\mathrm{V}$ when curing the anterior and posterior teeth (Figure 5A and B). On the other hand, the mean irradiance and radiant exposure values after-I were significantly higher than before-I when curing the posterior tooth (Figure 5C and D). Approximately $3 \%$ of the students that watched the $\mathrm{V}$ needed additional I by the examiner after completing the experiment.

Statistical comparisons between $\mathrm{V}$ and I instructional methods showed intriguing findings. The mean irradiance and radiant exposure values before-I were significantly higher than before- $\mathrm{V}$ when curing the anterior tooth (Figure 6A and $\mathrm{B}$ ). The mean irradiance and radiant 

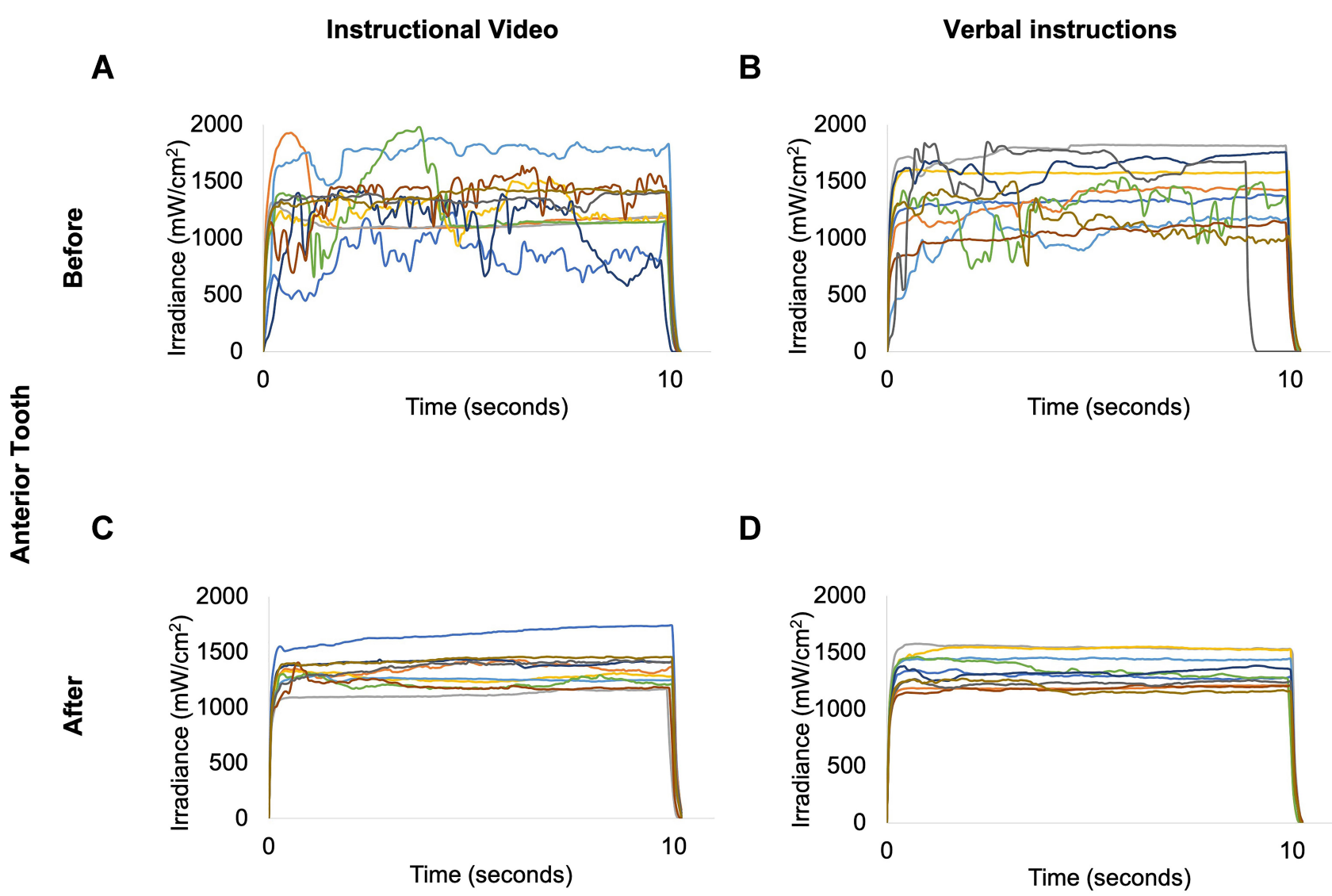

Figure 3 Representative irradiance $\left(\mathrm{mW} / \mathrm{cm}^{2}\right)$ measurements before and after the instructional video $(\mathrm{V})$ and verbal instructional $(\mathrm{I})$ methods using the anterior tooth on the Managing Accurate Resin Curing-Patient Simulator (MARC-PS) system. (A) Before-V. (B) After-V. (C) Before-I. (D) After-I.

exposure values after-I and after- $\mathrm{V}$ were not significantly different from each other regardless of the tooth cured (Figure 6C and D).

Comparing the percent differences before and after for each instructional method showed exciting findings. The percent increase in irradiance and radiant exposure values between instructional methods showed improvement when using the $\mathrm{V}$ compared to I. However, the differences were not significant, regardless of the tooth position (Table 1).

The correlation between the irradiance and radiant exposure values difference (after minus before) each student delivered by the designated instructional method, and their Preclinical Operative and Esthetic Dentistry course score was weak and not significant $(\mathrm{p}>0.05)$. The correlation using $\mathrm{V}$ ranged from -0.1 to 0.229 , and when using I, it ranged from -0.135 to 0.70 .

The comparison between V versus I based on the students' feedback was similar and not significant $(p=0.301)$. Students rated the designated method out of 5 , and results are presented in percentages with their common comments for each rating (Figure 7). The Figure showed that most of the students provided a rating of 4 and 5 , and $3 \%$ gave a rating of 3. Upon asking each student their learning preference and not limited to this experiment, a significantly higher percentage of the students preferred I (33\%) compared to V (24\%), and a group of students reported that both methods complemented each other (43\%). Students' responses and their common comments for each teaching method are presented in Figure 8.

Upon collecting feedback from the examiners, they reported that students performed better on the posterior tooth than the anterior tooth. Examiners' stated that students reported having better finger support for the LCU when curing the posterior tooth.

\section{Discussion}

Instructional videos are beneficial when teaching a larger number of students, where typically students are divided into groups, and an instructor is assigned for each group. Incorporating instructional videos in teaching reduces instructor fatigue as videos permit didactic rigor. ${ }^{16}$ 


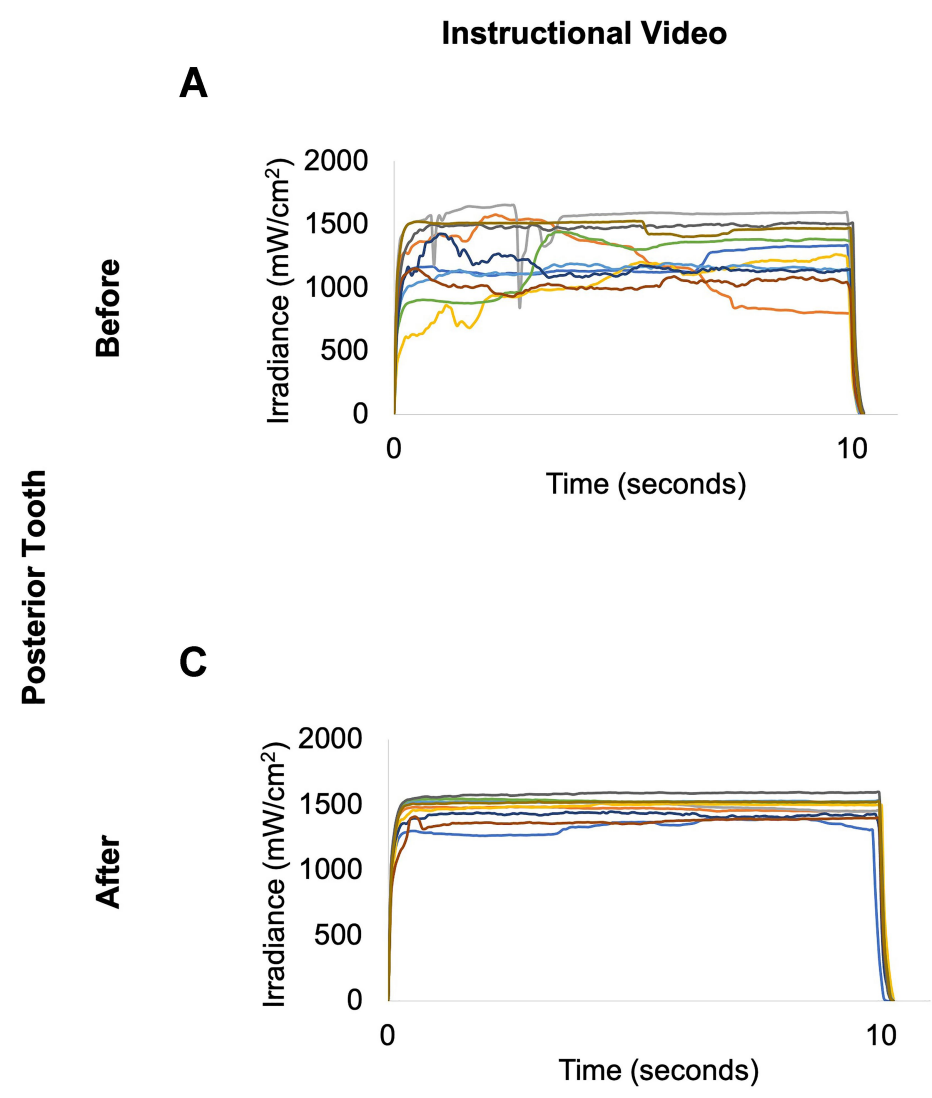

B

Verbal Instructions
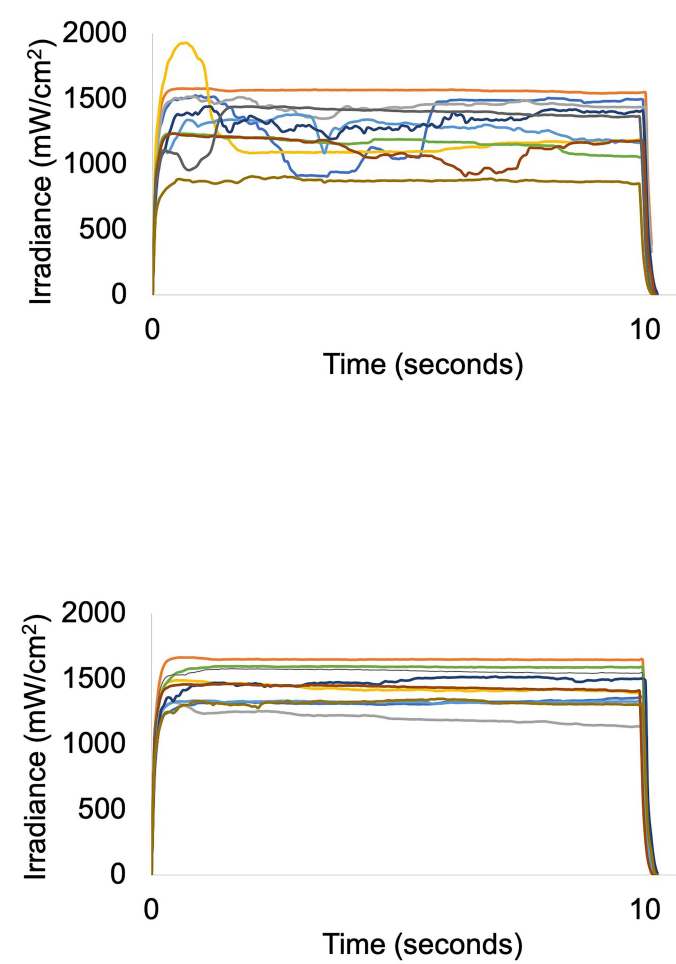

Figure 4 Representative irradiance $\left(\mathrm{mW} / \mathrm{cm}^{2}\right)$ measurements before and after the instructional video $(\mathrm{V})$ and verbal instructional $(\mathrm{I})$ methods using the posterior tooth on the Managing Accurate Resin Curing-Patient Simulator (MARC-PS) system. (A) Before-V. (B) After-V. (C) Before-I. (D) After-I.

Instructional videos also standardize the teaching content, ensure consistency, and allow students to see the intricate procedures clearly. ${ }^{16,30}$ Since dental procedures are precise and intricate, instructional videos would be very beneficial. Additionally, students can view sections of the video as needed, which has allowed a better opportunity for understanding the content, thus increasing the chance for deeper learning. ${ }^{15,16,19}$ This is especially true since often faculty in the same institute have typically graduated from different schools. Therefore, using instructional videos can be a way to calibrate the faculty and standardize teaching content. Besides, using video would be of particular value in this era with the development of the COVID-19 pandemic and the crucial need for social distancing.

Online teaching has become the primary way of learning because of the necessity of restricting students' existence in the academic buildings due to COVID-19 pandemic. ${ }^{31}$ Almost $90 \%$ of schools around Europe reported shifting to online (distance learning) by online lectures and live video streaming to cover dental courses' curriculum. ${ }^{31}$ The circumstances demanded practical solutions by the institutions with the existing resources; for example, $72 \%$ of schools used live or streamed videos in their education. ${ }^{31}$ However, preclinical and clinical training may not be entirely replaced with online teaching. ${ }^{32}$ This is especially true since the dental profession involves knowledge and cognitive learnings in addition to the development of psychomotor skills. ${ }^{33,34}$ In turn, changes in the simulation laboratory organization and clinic infrastructure may need to be changed to consider social distancing and isolation of units. Furthermore, smart devices give the students the privilege of being connected to their schedules and studies whenever and wherever they were. That would motivate students to self-learning by exploring the online resources available by scientific societies, such as clinical videos and webinars. ${ }^{32}$ These new educational methods may affect dental schools learning outcomes, and their impact should be measured for future references. ${ }^{31}$ Blending old with new educational methods could be considered as the cornerstone for the dental education future. ${ }^{32}$

Our study took place in an educational institute where all students' similar teaching experience must be ensured. Therefore, all students had the opportunity to use the MARC-PS after performing the light-curing technique 


\section{Irradiance}

A

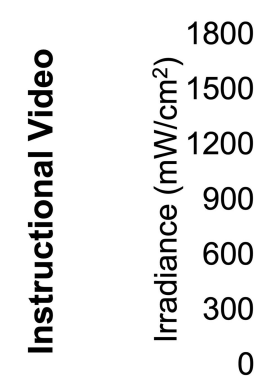

C

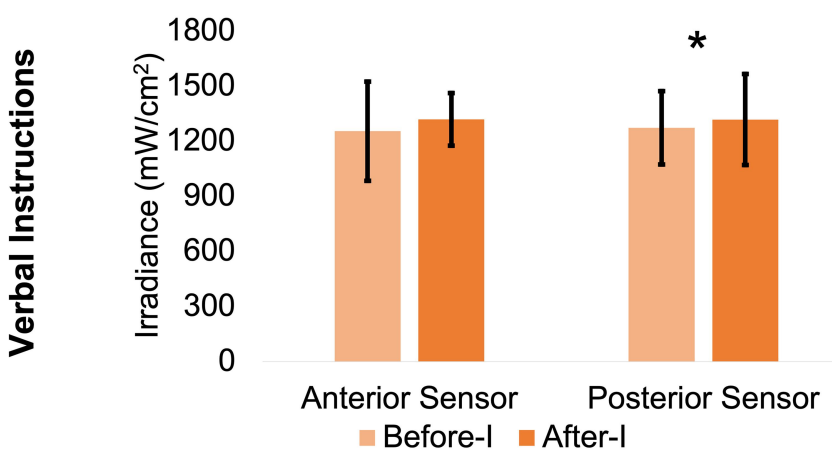

Radiant Exposure

B

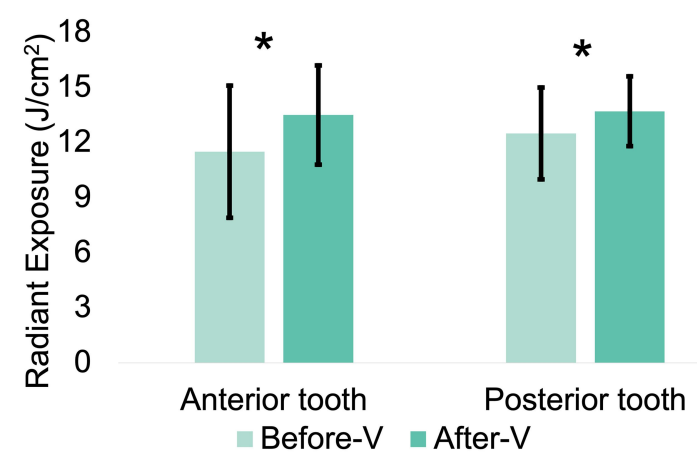

D

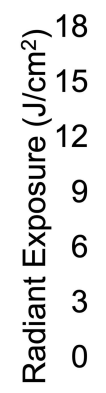

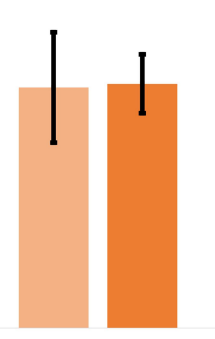

Anterior tooth $\square$ Before-I $\square$ After-I

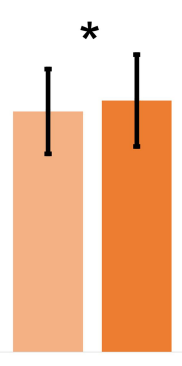

Posterior tooth

Figure 5 Comparison between the mean irradiance $\left(\mathrm{mW} / \mathrm{cm}^{2}\right)$ and radiant exposure $\left(\mathrm{J} / \mathrm{cm}^{2}\right)$ values before and after the instructional video $(\mathrm{V})$ and verbal instructional $(\mathrm{I})$ methods using the anterior and posterior teeth on the Managing Accurate Resin Curing-Patient Simulator (MARC-PS) system. (A) Irradiance values before- and after-V. (B) Radiant exposure values before- and after-V. (C) Irradiance values before- and after-I. (D) Radiant exposure values before- and after-I. Asterisk *represents significant differences between before- and after- each instructional method when curing each tooth.

twice before receiving one of the instructional methods, whether they were included in the study or not. A sample of 120 students was included in the study since it was the maximum number of students who could participate, allowing an equal number of students per gender in each group to eliminate gender bias. The students that were not included in the study were either part of the pilot study or did not wish to participate.

Examiners used the rubric as a checklist for the steps that were performed by students. Students' mistakes were related to various light-curing steps. Namely, checking the light-guide tip is clean and not broken, placing the bluelight blockers on the patient simulator, placing the lightguide tip perpendicular to the surface as close as possible, placing finger support, and keeping the eyes on the filling while curing. Students' inability to execute each lightcuring step accurately or missing a step is expected. This can be because students are learning a new procedure.
Students that did not wear the blue-light blocker googles looked away from the tooth being cured upon the lightcuring procedure, although they knew the importance of wearing the goggles. Another study showed similar observations. ${ }^{1}$

The incorporation of a $\mathrm{V}$ compared to $\mathrm{I}$ to teach the light-curing technique showed interesting findings. In general, the mean irradiance values measured by the expert was higher than those recorded by the students regardless of the tooth cured, which is expected since it is the first exposure for students to light-curing. A similar trend was observed in other studies. ${ }^{1,35}$ Regardless of the instructional method used or the tooth position, the mean irradiance values the students who delivered to the simulated cavities were over $400 \mathrm{~mW} / \mathrm{cm}^{2}$, which is the minimal amount of accepted irradiance according to the International Standards Organization (ISO 10650-2), to 


\section{Irradiance}

A

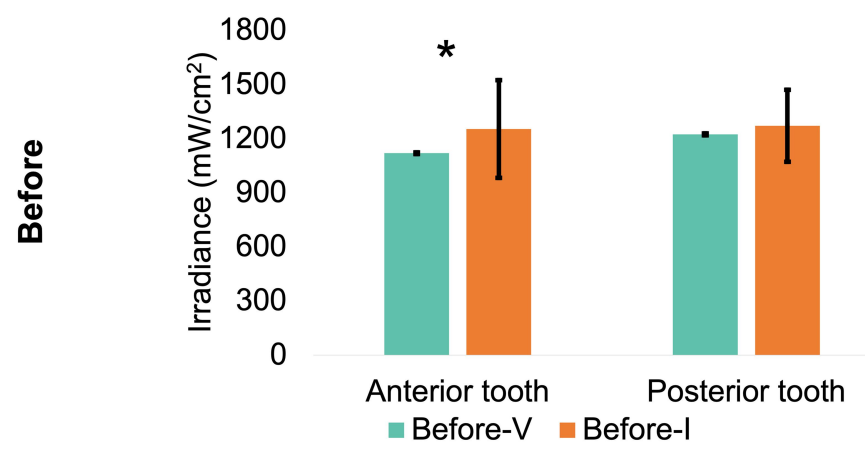

C

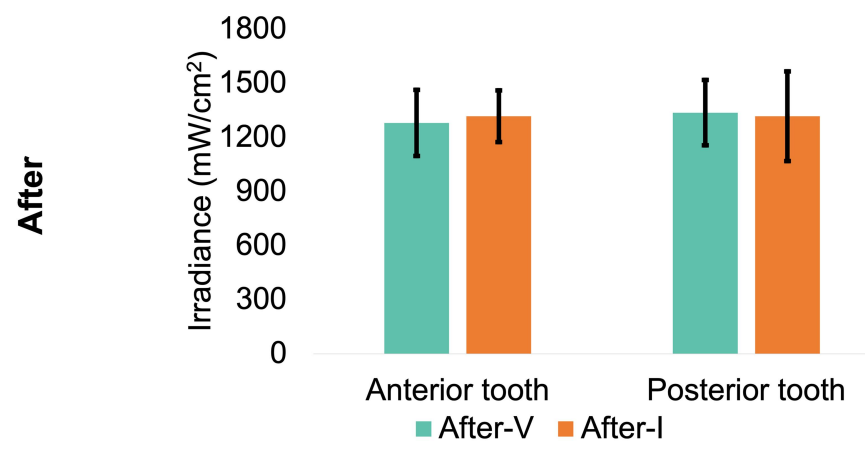

\section{Radiant Exposure}

B

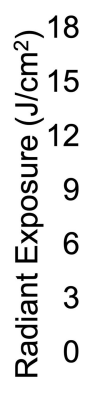

D

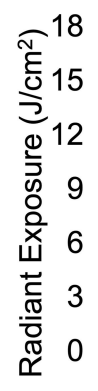

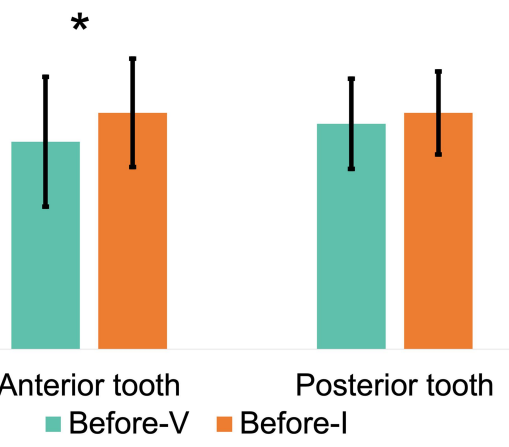

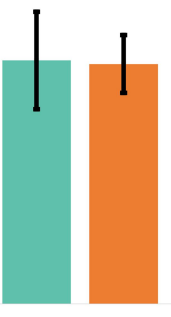

Anterior tooth After-V $\backsim$ After-I

Figure 6 Comparisons between the mean irradiance $\left(\mathrm{mW} / \mathrm{cm}^{2}\right)$ and radiant exposure $\left(\mathrm{J} / \mathrm{cm}^{2}\right)$ of the instructional video $(\mathrm{V})$ and verbal instructional $(\mathrm{I})$ methods using the anterior and posterior teeth on the Managing Accurate Resin Curing-Patient Simulator (MARC-PS) system. (A) Mean irradiance values before-V and -I. (B) Mean radiant exposure values before- $\mathrm{V}$ and $-\mathrm{I}$. (C) Mean irradiance values after-V and -I. (D) Mean radiant exposure values after-V and $-\mathrm{I}$. Asterisk *represents significant differences between $\mathrm{V}$ and $\mathrm{I}$ instructional methods when curing each tooth.

effectively activate polymerization of a $2-\mathrm{mm}$ increment of a conventional RBC. ${ }^{36}$

Visual improvement was evident in the irradiance graphs before and after for each method for each tooth. Our results were similar to the literature, which was conclusive that verbal coaching instruction improved students' light-curing performance. ${ }^{1,27,35,37,38}$ The students' feedback for having better finger support stability can explain the superior students' performance when light-curing the posterior tooth compared to the anterior, as shown in the graphs. Our results were similar to a study in the literature which concluded that there was no significant difference in the mean skills test scores, between a procedural instructional video, compared to a live demonstration in prosthodontics teeth setting, orthodontics, and orthodontics wire bending. $8,10,12,39$

Table I Percent Increase in Irradiance $\left(\mathrm{mW} / \mathrm{cm}^{2}\right)$ and Radiant Exposure $\left(\mathrm{J} / \mathrm{cm}^{2}\right)$ Values Using the Instructional Video (V) Compared to the Verbal Instructions (I) as Detected by the Anterior and Posterior Teeth on the Managing Accurate Resin Curing-Patient Simulator (MARC-PS) System

\begin{tabular}{|l|l|l|l|}
\hline Parameter & Sensor & Instructional Videos (V) (\%) & Verbal Instructions (I) (\%) \\
\hline Mean irradiance $\left(\mathrm{mW} / \mathrm{cm}^{2}\right)$ & Anterior & 14.32 & 5.10 \\
& Posterior & 9.25 & 3.56 \\
\hline Radiant Exposure $\left(\mathrm{J} / \mathrm{cm}^{2}\right)$ & Anterior & 17.79 & 1.76 \\
& Posterior & 9.51 & 4.28 \\
\hline
\end{tabular}

Notes: No significant differences were observed in the percent increase between instructional video compared to verbal instructions per the measurements obtained for each sensor. The percent increase was calculated from the (after minus before) measurements obtained from each sensor for each instructional method. 


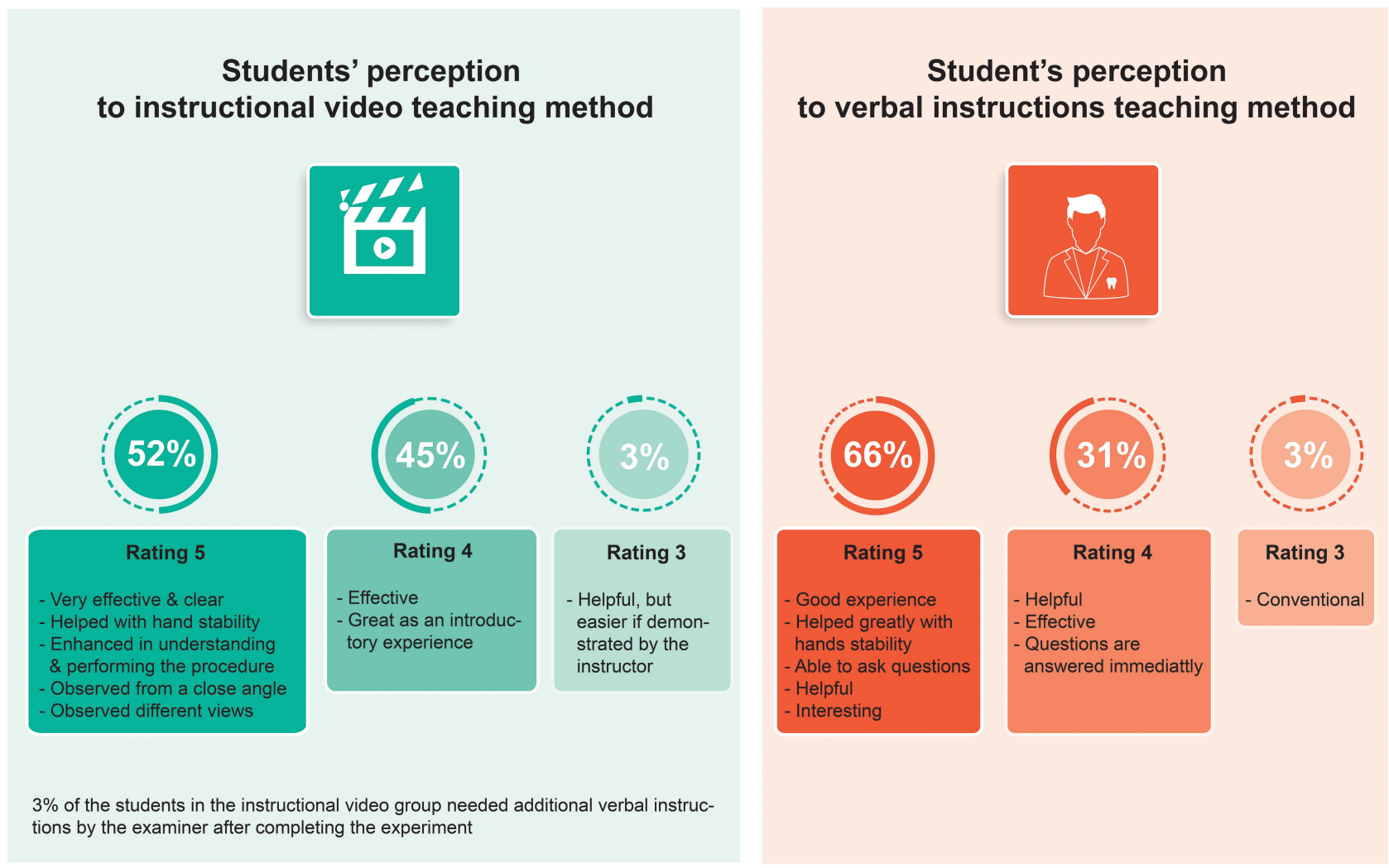

Figure 7 Students' perception responses on the instructional video $(\mathrm{V})$ and verbal instructional $(\mathrm{I})$ methods. Percentages, ratings, and comments were obtained from the feedback survey distributed to students after completing the experiment.

The mean radiant exposure the students delivered was between $11.5-13.7 \mathrm{~J} / \mathrm{cm}^{2}$ regardless of the instructional method or tooth position. There were $3.33 \%$ of students delivered radiant exposure values of less than $6 \mathrm{~J} / \mathrm{cm}^{2}$. It was shown that $6 \mathrm{~J} / \mathrm{cm}^{2}$ was the minimum amount of radiant exposure needed for sufficient polymerization. ${ }^{25,35}$ Studies reported that $10-20 \mathrm{~J} / \mathrm{cm}^{2}$ was sufficient to polymerize RBC effectively. ${ }^{40-44}$ However, the amount of radiant exposure the restoration need differs according to the type, shade, and opacity of the RBC. ${ }^{2,345}$ It is important to note that the radiant exposure results will differ with increasing the curing time $($ radiant exposure $=$ irradiance $\times$ time $) .{ }^{3}$ Therefore, students would deliver higher amounts of radiant exposure when the curing time is increased. This is evident in other studies that investigated the students' light-curing performance over 20 seconds. ${ }^{24}$ The 10 second curing time was selected according to the manufacturers' recommendation of the RBC used in the preclinical laboratory. The curing time selected was similar to another study. ${ }^{27}$ Movement of the light-guide tip over the surface being cured or placing it at an angle can negatively impact the amount of irradiance the restoration receives. This was evident in the graphs
(Figures 3 and 4) before receiving instructions. Subsequently affecting the amount of radiant exposure values received by the simulated cavities, as evident in Figures 5 and 6. Consequently, potentially affecting the polymerization activation effectiveness as reported in the literature. ${ }^{3,25,35}$ The current study results were partially similar to a study that reported that students delivered a mean of $13.2 \mathrm{~J} / \mathrm{cm}^{2}$ as detected by the posterior tooth after receiving verbal instruction. ${ }^{1}$ And similar to a study that reported approximately a $3 \%$ increase in the radiant exposure delivered by students after receiving verbal instruction. ${ }^{35}$ Our results were different from a study that reported students delivered an approximate mean radiant exposure value of 6 $\mathrm{J} / \mathrm{cm}^{2.27,38}$ The difference in radiant exposure the students delivered, between our study and the literature, may be due to the different LCUs used and the selected curing times.

For each instructional method, the $\mathrm{V}$ instructional method's statistical comparisons showed that the mean irradiance and radiant exposure were significantly higher after- $\mathrm{V}$ than before- $\mathrm{V}$ as detected by the anterior and posterior teeth. For the I instructional method, the results showed a significant difference for the mean irradiance 


\section{Students' Learning Preference}

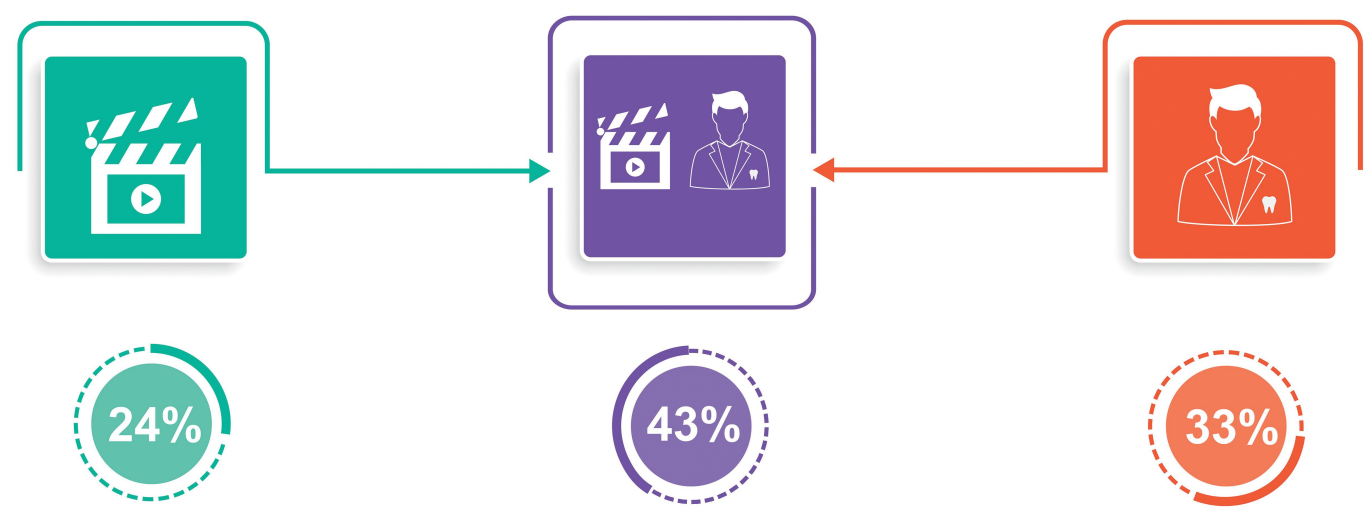

Why students prefer video instructions?
Standardization
- Information and instructions are standardized
Clarity
- Clearer than verbal instructions
- See the procedure zoomed in with all its details
- Avoid missing important information
Convenience
- Easier
- Individual view unlike the instructor demonstration
- Prevents overcrowding around instructors
- Freedom to watch and review at anytime and
anywhere (stop, pause, rewind ant any point)
Efficiency
- Save time
- Language is usually clearer
- Revise and prepare for better execution

Why students prefer both?

Both teaching methods comple-

mented each other and gave the best result when combined

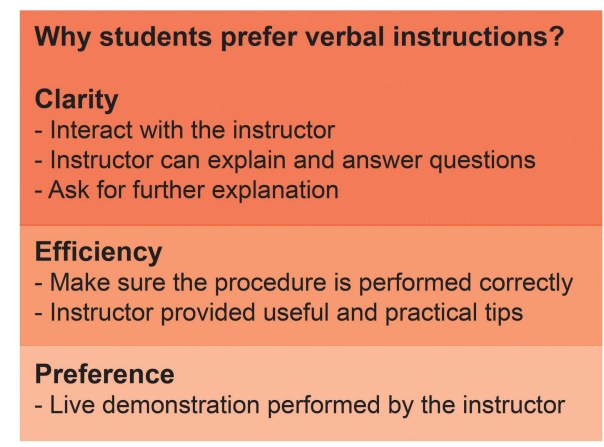

Figure 8 Students' learning preference. Percentages and comments were obtained from the feedback survey distributed to students after completing the experiment.

and radiant exposure values after-I than before-I when light-curing the posterior tooth. This may be explained by the better finger support students reported to the examiners when curing the posterior tooth compared to the anterior. This can also indicate that the I group students performed better (before-I) than students in the V group (before-V), which is noticeable in the percent increase differences in the measurements between both instructional methods.

Comparisons between V and I methods showed interesting findings. There was an increase in the mean irradiance and radiant exposure values the students delivered that was significant before both methods when curing the anterior tooth. Nevertheless, there were no significant differences after both methods. Therefore, the first and second working hypotheses were partially accepted. This indicated that $\mathrm{V}$ was comparable to I for teaching the light-curing technique. The non-significant differences between instructional methods could be due to the variation in the recorded measurements masking either methods' impact.

Based on the students' survey feedback on their perception of the designated teaching method, the majority rated 4 and 5, and 3\% gave a rating of 3 regardless of the teaching method used. Most of the students' feedback regarding $\mathrm{V}$ was related to the clarity and closeup view that helped them understand and see the technique from different angles and enhanced the understanding of the procedure. However, students in the I group also provided 4 and 5 ratings for the method. The main comments were that the method was helpful, and they can have their questions answered, and challenging issues clarified immediately by the instructor. Some students reported that they found video instructions beneficial, but they preferred verbal instructions and vice versa. This was evident when examiners commented that video 
instructions were not sufficient for $3 \%$ of the students where they needed additional verbal instructions after the video instructions. This is most likely because students mentioned that they could not grasp the information solely from the video instructions.

Based on the students' learning preference, some students preferred I, others $\mathrm{V}$, and a group of students preferred both methods as they complemented each other. Using V had an added benefit based on the students' feedback because the teaching content would be standardized, and laboratory time would be used more efficiently. Therefore, videos would improve the learning experience as students would have the video to refer back to whenever needed. In addition, using instructional videos as a teaching method can provide an added value by utilizing session time more efficiently. On the other hand, students who preferred I mentioned that it was clear, and they can ask questions and get clarifications from the instructor. Each method can accommodate different learning preferences, where $43 \%$ of the students reported that they prefer $\mathrm{V}$ and I methods combined to maximize their learning experience. This was not surprising since it has been reported in the literature that students have different learning preferences. ${ }^{13,14}$ After completing the experiment and analyzing the results, the outcomes were shared with students in a lecture. Some students were surprised with the study results but favored their original learning preference regardless of the outcomes. It is important to note that the results may vary in a clinical setting to some extent due to the various challenges encountered with patients, including variation in patient mouth opening, patient apprehension to treatment, type of isolation, and the size and angulation of the LCU guide tip.

The course grade includes assessments of the different domains through didactic and preclinical components. The didactic component included summative assessments performed throughout the year in quizzes, midyear, final and objective structured practical examinations. In addition to different assignments, integrated sessions, and group presentations. The practical components comprised of assessing different procedures that included preparation of different cavity classes and designs, restorations, adjunctive procedures, and competencies. A weak correlation between the difference (after minus before) in the students' ability to deliver sufficient irradiance and radiant exposure and their course scores was shown. This can be explained by the fact that the students' scores represent the didactic and practical components, and the current experiment was focused on a psychomotor skill. Therefore, the third working hypothesis was partially accepted. Our results were similar to studies that showed no correlation between the student's didactic scores compared to their psychomotor skills. ${ }^{34,46}$ Possible limitations to the study are that due to scheduling restrictions, the experiment took place in the laboratory during the sessions, which took place at different times during the same week. This may have impacted the students' performance to some extent.

Based on the study outcomes, the institute would continue to use instructional videos as one of the teaching method in the course. Additional verbal instructions would be provided to the group of students who watched the videos and needed additional instructions to accommodate the different learning preferences. Furthermore, a light-curing procedure and maintenance checklist would be provided to the student as a reference in addition to the detailed rubric provided in the laboratory assessment booklet. Further research would include exploring the students' LCU performance technique clinically; however, the irradiance and radiant exposure will not be measured without the MARC-PS spectrometer. Moreover, after a few years, retesting students to evaluate both groups' retention would be interesting. Investigating students' self-efficacy would also be valuable.

\section{Conclusion}

An instructional video in addition to didactic lectures to teach the light-curing technique to undergraduate dental students was comparable to traditional verbal instructions and did not significantly impact student ability to deliver sufficient irradiance and radiant exposure values to the simulated cavities. The instructional video was useful for teaching light-curing per the students' feedback. There was no significant correlation between the students' ability to deliver sufficient irradiance and radiant exposure values and their course scores. Using instructional videos as a teaching method can provide an added value by utilizing session time more efficiently. Furthermore, it would be of critical importance with the current need for social distancing during the COVID-19 pandemic.

\section{Abbreviations}

LCU, Light-curing unit; MARC-PS, Managing Accurate Resin Curing-Patient Simulator; V, instructional video; I, verbal instruction; RBC, resin-based composite. 


\section{Acknowledgments}

The authors would like to thank Dr. Razan N. Alharbi, Dr. Kholood A. Alhussami, Dr. Zuhair Natto, Dr. Rozana A. Al-Bukhary, Mrs. Deema Meisha, and Mr. Osama A. Dhawi for their help and technical support.

\section{Disclosure}

All authors report no conflicts of interest in this work.

\section{References}

1. Federlin M, Price R. Improving light-curing instruction in dental school. J Dent Educ. 2013;77(6):764-772. doi:10.1002/j.00220337.2013.77.6.tb05528.x

2. Price RB, Ferracane JL, Shortall AC. Light-curing units: a review of what we need to know. J Dent Res. 2015;94(9):1179-1186. doi:10.1177/0022034515594786

3. Leprince JG, Palin WM, Hadis MA, et al. Progress in dimethacrylate-based dental composite technology and curing efficiency. Dent Mater. 2013;29(2):139-156. doi:10.1016/j. dental.2012.11.005

4. Calheiros FC, Daronch M, Rueggeberg FA, et al. Degree of conversion and mechanical properties of a BisGMA: TEGDMA composite as a function of the applied radiant exposure. $J$ Biomed Mater Res B Appl Biomater. 2008;84(2):503-509. doi:10.1002/jbm.b.30897

5. Lohbauer U, Rahiotis C, Kramer N, et al. The effect of different light-curing units on fatigue behavior and degree of conversion of a resin composite. Dent Mater. 2005;21(7):608-615. doi:10.1016/j. dental.2004.07.020

6. Ferracane JL, Mitchem JC, Condon JR, et al. Wear and marginal breakdown of composites with various degrees of cure. $J$ Dent Res. 1997;76(8):1508-1516. doi:10.1177/00220345970760081401

7. Zhu S, Platt JA. Curing efficiency of three different curing lights at different distances for a hybrid composite. Am J Dent. 2009;22 (6):381-386.

8. Thilakumara IP, Jayasinghe RM, Rasnayaka SK, et al. Effectiveness of procedural video versus live demonstrations in teaching laboratory techniques to dental students. J Dent Educ. 2018;82(8):898-904. doi:10.21815/JDE.018.086

9. Packer ME, Scott BJ, Davis DM. An assessment of the influence of clinical demonstrations on the confidence of undergraduate dental students, when treating patients requiring removable partial dentures. Eur J Dent Educ. 1999;3(3):133-139. doi:10.1111/j.16000579.1999.tb00079.x

10. Alqahtani ND, Al-Jewair T, Al-Moammar K, et al. Live demonstration versus procedural video: a comparison of two methods for teaching an orthodontic laboratory procedure. BMC Med Educ. 2015;15(1):199. doi:10.1186/s12909-015-0479-y

11. Brame CJ. Effective educational videos: principles and guidelines for maximizing student learning from video content. CBE Life Sci Educ. 2016;15(4). doi:10.1187/cbe.16-03-0125

12. Atik E, Gorucu-Coskuner H, Taner T. The effect of live-video demonstration on dental students' orthodontic bending performance. J Dent Educ. 2019.

13. Vaughn L, Baker R. Teaching in the medical setting: balancing teaching styles, learning styles and teaching methods. Med Teach 2001;23(6):610-612. doi:10.1080/01421590120091000

14. ALQahtani DA, Al-Gahtani SM. Assessing learning styles of Saudi dental students using Kolb's learning style inventory. J Dent Educ. 2014;78(6):927-933. doi:10.1002/j.0022-0337.2014.78.6.tb05747.x

15. Fakhry A, Cooper S, Slach N, et al. Video-assisted clinical instruction in dentistry. Overview and applications. Eur J Dent Educ. 2007;11 (4):230-237. doi:10.1111/j.1600-0579.2007.00461.x
16. Wong G, Apthorpe HC, Ruiz K, et al. An innovative educational approach in using instructional videos to teach dental local anaesthetic skills. Eur J Dent Educ. 2019;23(1):28-34. doi:10.1111/eje.12382

17. Kenny KP, Alkazme AM, Day PF. The effect of viewing video clips of paediatric local anaesthetic administration on the confidence of undergraduate dental students. Eur J Dent Educ. 2018;22(1):e57-e62. doi:10.1111/eje.12257

18. Kalwitzki M, Rosendahl R, Gottle R, et al. Acceptance of video-based teaching in paediatric dentistry by undergraduate dental students. Eur J Dent Educ. 2003;7(2):66-71. doi:10.1034/j.16000579.2003.00286.x

19. Fakhry A, Dehkordi-Vakil FH. Video-Assisted Clinical Instruction in Dentistry (VACID) enhances real-time visualisation of clinical procedures. Eur J Dent Educ. 2007;11(4):238-244. doi:10.1111/ j.1600-0579.2007.00465.x

20. Clancy JM, Lindquist TJ, Palik JF, et al. A comparison of student performance in a simulation clinic and a traditional laboratory environment: three-year results. $J$ Dent Educ. 2002;66(12):1331-1337. doi:10.1002/j.0022-0337.2002.66.12.tb03606.x

21. Green TG, Klausner LH. Clinic simulation and preclinical performance. J Dent Educ. 1984;48(12):665-668. doi:10.1002/ j.0022-0337.1984.48.12.tb01845.x

22. Perry S, Bridges SM, Burrow MF. A review of the use of simulation in dental education. Simul Healthc. 2015;10(1):31-37. doi:10.1097/ SIH.0000000000000059

23. Soares CJ, Rodrigues MP, Vilela AB, et al. Evaluation of eye protection filters used with broad-spectrum and conventional LED curing lights. Braz Dent J. 2017;28(1):9-15. doi:10.1590/01036440201701380

24. Samaha S, Bhatt S, Finkelman M, et al. Effect of instruction, light curing unit, and location in the mouth on the energy delivered to simulated restorations. Am J Dent. 2017;30(6):343-349.

25. Price RB, Felix CM, Whalen JM. Factors affecting the energy delivered to simulated class I and class V preparations. J Can Dent Assoc. 2010;76:a94.

26. Tauböck TT, Par M, Attin T, et al. Effectiveness of using a patient simulator with real-time feedback to improve light-curing skills of dental students. Appl Sci. 2020;10.

27. Price RB, Strassler HE, Price HL, et al. The effectiveness of using a patient simulator to teach light-curing skills. J Am Dent Assoc. 2014;145(1):32-43. doi:10.14219/jada.2013.17

28. Suliman AA, Abdo AA, Elmasmari HA. Training and experience effect on light-curing efficiency by dental practitioners. $J$ Dent Educ. 2020;84(6):652-659. doi:10.1002/jdd.12113

29. Albino JE, Young SK, Neumann LM, et al. Assessing dental students' competence: best practice recommendations in the performance assessment literature and investigation of current practices in predoctoral dental education. $J$ Dent Educ. 2008;72(12):1405-1435. doi:10.1002/j.0022-0337.2008.72.12.tb04620.x

30. van Det MJ, Meijerink WJ, Hoff C, et al. The learning effect of intraoperative video-enhanced surgical procedure training. Surg Endosc. 2011;25(7):2261-2267. doi:10.1007/s00464-010-1545-5

31. Quinn B, Field J, Gorter R, et al. COVID-19: the immediate response of european academic dental institutions and future implications for dental education. Eur J Dent Educ. 2020;24(4):811-814. doi:10.1111/ eje. 12542

32. Bennardo F, Buffone C, Fortunato L, et al. COVID-19 is a challenge for dental education-a commentary. Eur J Dent Educ. 2020;24 (4):822-824. doi:10.1111/eje.12555

33. Hildebrandt GH, Belmont MA. Self-paced versus instructor-paced preclinical training in operative dentistry: a Case Study. $J$ Dent Educ. 2018;82(11):1178-1184. doi:10.21815/JDE.018.122

34. Afify AR, Zawawi KH, Othman HI, et al. Correlation of psychomotor skills and didactic performance among dental students in Saudi Arabia. Adv Med Educ Pract. 2013;4:223-226. doi:10.2147/AMEP. S53319 
35. Price RB, McLeod ME, Felix CM. Quantifying light energy delivered to a class I restoration. J Can Dent Assoc. 2010;76:a23.

36. ISO. 10650-2:2007. Dentistry-powered polymerization activators: part 2: light-emitting diode (LED) lamps. Geneva, Switzerland: International Standards Organization; 2007:7.

37. Balhaddad AA, Marghalani AA, Raderman M, et al. Hands-on training based on quantifying radiant exposure improves how dental students cure composites: skill retention at 2-year follow up. Eur $J$ Dent Educ. 2020. doi:10.1111/eje.12635

38. Seth S, Lee CJ, Ayer CD. Effect of instruction on dental students' ability to light-cure a simulated restoration. J Can Dent Assoc. 2012;78:c123.

39. Gorucu-Coskuner H, Atik E, Taner T. Comparison of live-video and video demonstration methods in clinical orthodontics education. J Dent Educ. 2019.

40. Chye CH, Yap AU, Laim YC, et al. Post-gel polymerization shrinkage associated with different light curing regimens. Oper Dent. 2005;30(4):474-480.

41. Anusavice KJ, Shen C, Rawls HR. Phillip's Science of Dental Materials. St. Louis, MO: Saunders; 2013.
42. Al-Zain AO, Eckert GJ, Lukic H, et al. Polymerization pattern characterization within a resin-based composite cured using different curing units at two distances. Clin Oral Investig. 2019;23 (11):3995-4010. doi:10.1007/s00784-019-02831-1

43. Al-Zain AO, Eckert GJ, Platt JA. The influence of distance on radiant exposure and degree of conversion using different light-emitting-diode curing units. Oper Dent. 2019;44(3):E133-E144. doi:10.2341/18-004-L

44. Al-Zain AO, Eckert GJ, Lukic H, et al. Degree of conversion and cross-link density within a resin-matrix composite. J Biomed Mater Res B Appl Biomater. 2018;106(4):1496-1504. doi:10.1002/jbm. b. 33960

45. Rueggeberg FA, Giannini M, Arrais CAG, et al. Light curing in dentistry and clinical implications: a literature review. Braz Oral Res. 2017;31(suppl 1):e61. doi:10.1590/1807-3107bor-2017. vol31.0061

46. Zawawi KH, Afify AR, Yousef MK, et al. Reliability of didactic grades to predict practical skills in an undergraduate dental college in Saudi Arabia. Adv Med Educ Pract. 2015;6:259-263. doi:10.2147/ AMEP.S72648
Advances in Medical Education and Practice

\section{Publish your work in this journal}

Advances in Medical Education and Practice is an international, peerreviewed, open access journal that aims to present and publish research on Medical Education covering medical, dental, nursing and allied health care professional education. The journal covers undergraduate education, postgraduate training and continuing medical education

\section{Dovepress}

including emerging trends and innovative models linking education, research, and health care services. The manuscript management system is completely online and includes a very quick and fair peer-review system. Visit http://www.dovepress.com/testimonials.php to read real quotes from published authors. 